\title{
Anxiety from a Work Conflict May Be Exacerbated by Lack of Knowledge of Work Life Rules-A Case Series
}

\author{
John E. Berg \\ Faculty of Health Sciences, Oslo Metropolitan University, Oslo, Norway \\ Email: john@pong.no
}

How to cite this paper: Berg, J.E. (2019) Anxiety from a Work Conflict May Be Exacerbated by Lack of Knowledge of Work Life Rules-A Case Series. Open Journal of Psychiatry, 9, 215-219.

https://doi.org/10.4236/ojpsych.2019.93016

Received: April 3, 2019

Accepted: May 27, 2019

Published: May 30, 2019

Copyright (อ 2019 by author(s) and Scientific Research Publishing Inc. This work is licensed under the Creative Commons Attribution International License (CC BY 4.0).

http://creativecommons.org/licenses/by/4.0/

\section{c) (i) Open Access}

\begin{abstract}
Job performance is dependent on a multitude of factors in the work place, the personal characteristics of the employees and the personal performance or leading strategies of the employer. Food retail shops in Norway are staffed with young persons, often students seeking part time jobs. Trade union membership is rare, and occupational health service is distant if existing at all. The aim was to present the development of three young workers in relation to the handling of length and timing of workdays and sickness absence. All three were referred to a private psychiatric practice because of increasing anxiety and depressive traits. Two had symptoms interfering with their academic study performance leading to sickness absence. A hitherto unknown bipolar disorder became evident and needed medication and further psychotherapy. The unfavourable work environment was deemed the most probable provoking factor for the reduction in functional performance in these otherwise healthy young students.
\end{abstract}

\section{Keywords}

Work Environment, Anxiety, Functional Ability, Exploitation

\section{Background}

Job performance is dependent on a multitude of factors in the work place. Personal characteristics of the employees and the performance or leading strategies of the employer are other factors. Within healthcare-facilities part time work is also prevalent. Workers may be overloaded and stressed more than in facilities with mainly full time workers, as shown by Stevenson and Duxbury [1]. They listed 12 overload situations that contributed to stress. Among Danish knowl- 
edge workers (people working with sign, communication or exchange of knowledge) it was shown that both work environmental and individual characteristics should be taken into account in order to capture sources of stress in modern working life [2]. In retail business, part-time work is also prevalent and young people, often students, seek jobs that may be combined with studies. Overload on workers is observed although these young workers are flexible and eager to earn. Their knowledge of the rules of working hours, overtime pay and paid sick leave is fragmentary. Employers may unknowingly or on purpose take advantage of this.

Norway is a country with strong, strict and detailed rules for employee and employer interactions. The trade union membership rate is among the highest in Europe. Daily work hours are regulated and work time exceeding a normal time frame must be remunerated above normal pay. Sick leave certified by a medical doctor is by law to be paid by the employer during the first 16 days, thereafter by the National health insurance at $100 \%$ of normal pay for up to 50 weeks. Many young and inexperienced workers do not know their rights. They can be unknowingly exploited. Some of these young workers may be psychosocially vulnerable, which would normally not be relevant for the functioning in a part time retail job. A Pub-Med search did not turn out many relevant articles for these topics.

The aim of the study was to present the psychiatric development of three young workers in relation to the handling of length and timing of workdays and sickness absence in a food retail shop.

\section{Case Presentations}

The author had therapeutic talks with the following three cases at fortnightly intervals for more than a year. Somatic investigations and blood tests were taken by their GPs and found normal and are therefore omitted in this paper.

Cases:

The first case is a female shop assistant, 25 years old. She holds a bachelor degree in marketing. Her mother and father divorced when she was 9 years old. She has a complicated relationship to her father. During her first period in the retail shop she collaborated well with her employer because of a capacity to work a lot. When she became depressed after a time with work overload, she was met with stricter rules. He did not accept sickness absence, although he got the certificate from her medical doctor. The employer tried to force her back to the job, indicating that it was difficult to run the shop without her. The doctor contacted his superiors in the retail shop chain and informed that this practice was against the law. She continued with periods where she worked a lot with ease and other periods where she was depressed. The psychiatrist diagnosed a bipolar disorder in need of medical treatment. Her score on the Beck Depression Inventory (BDI) was severe depression. The BDI was normalized after half a year on relevant medication (lamotrigine and low-dose flupentixol). She eventually got higher 
pay, but the employer continued to pressure her to work more than scheduled hours during periods when she was in need to rest. She had both mental and physical reactions as fainting behind the cashier desk. Her condition stabilized on the prescribed medications but her vulnerability did not taper completely off. Thus, she again had sickness absence until she found another job.

The second case is a female shop assistant, 23 years old, studying informatics and law. Three siblings, one addicted to drugs and she has felt a special responsibility for him. She is working part time and has conflicts with the employer over work schedule planning. Several times she had to skip lectures to attend the work schedule. The employer has not given out work schedules more than one week in advance. Her study results have been worse than her deemed ability. She did not ask for a sick leave certificate. She did not develop any psychopathology in need of special pharmacological intervention, but her mood was shifting from session to session without obvious explanations. Her academic achievement was below expectations for the current academic year. The following academic year she stopped working at this retail shop.

The third case is a female shop assistant, 24 years old, preparing for further studies. Her mother had anorectic behaviour and depression, and her father was depressed and later underwent an operation for a myocardial infarction giving her great concern. She is very attached to her parents and does her utmost to satisfy and help them. At work, she was eager to do her best and did accept all changes in work schedules. She did not manage to stand up for her own good, not at home and not at work. The employer refused to give her less hours of work before the exam periods. She underachieved on exams. The employer also tried to convince her to withdraw the sickness leave certification. She was diagnosed with a depressive disorder with dependent personality traits and used an antidepressant (sertraline). Finally, being able to enter the studies she wanted, she stopped working at the retail shop. But she had to continue with sertraline.

All cases were asked to estimate the degree of own health problems they related to the work environment. They did so on a scale from 0 to 100 , with 0 being no relation of health problems to the work environment. The author did the same before asking the cases based on the psychiatric evaluation and knowledge of the work place with a background in occupational medicine, Table 1 . The estimates were not very different, but with a tendency towards the author attributing more problems to the work place. A survival strategy may have contributed to the lower estimated problems related to the work environment.

Table 1. Estimated percentage of health problems related to work environment.

\begin{tabular}{cccc}
\hline & Case 1 & Case 2 & Case 3 \\
\hline Case estimate & 60 & 70 & 50 \\
Authors estimate & 80 & 60 & 80 \\
\hline
\end{tabular}




\section{Discussion}

Occupational health services monitor the work environment by standardized measurements and interviews with employers and employees, if they can enter the work place. The setting may be an odd one. The method of this study circumvents this. All three referred cases represented serious, trustworthy, reliable and young women working in a food retail shop that is part of a bigger chain of shops. The employer runs his shop independently of the chain, as a franchise. His financial results are monitored by the chain, but not his way of using staff. Trade unions are weak, especially among the young who are students. None of the cases were members of a union. The three were deemed not to profit in any way from not telling the author how they experienced working in the retail shop.

The three cases illustrate different areas where the employer twists rules of law covering work place relations. This is corroborated in a very recent book by Jeffrey Pfeffer entitled Dying for a pay check (Harper Collins Business 2018). Half the workers meant that job-related stress affected performance whereas only $5 \%$ of employers bothered to do anything with it. Employees were eager to help, but employers did not plan working hours in advance. The provision of universal health care, as in Norway, did not secure rule-based management. Probably because the employer could get by with it as the employees did not know their common rights. Employers may rely on the easy substitutability of workers, so no hoarding of a work force was necessary.

In case one the employer did not accept sickness certificate from her doctor. This is illegal. He also let her work more than regular work hours without the usual overtime pay. After the intervention by the doctor to his superiors his behaviour gradually changed.

In case two he used work schedules to force her to work, at short notice, at hours inconvenient to her.

In case three he also used mental pressure to let her work during the time she prepared for exams.

He did not invite the trade union to organize the workers.

The employer, the leader of the shop may have little support for his way of supervising the employees. This may be an explanation of the behaviour at this shop [3].

In a large review of the working conditions and occupational health of immigrant workers in Europe and Canada work injuries were consistently found to be more prevalent among immigrants [4]. However, the evidence for working conditions as a potential mediator of the association between immigrant status and poor general health and mental distress was very limited. This contrasts with the findings of this case study where the members were not immigrants, white, but with a vulnerable background. This background provoked worsening of health when encountering the leadership strategy of the shop. It has previously been shown that big health care companies deliberately run the facilities according to a plan that reduce work place satisfaction even at higher costs [5]. 
Musculoskeletal discomfort often develops in grocery stores as the present shop. The present three employees did not report this as a main problem at work [6]. As they all contacted a psychiatrist, their focus was on mental health problems. Even so, one of the cases developed different somatic symptoms as fainting, pain in arms and shoulder during work hours.

\section{Conclusion}

This case series illustrates the worsening of light to moderate mental health problems in a work environment not following the Law of working conditions. The anxiety in the three cases led to the referral to a psychiatrist. Two of the three cases had conditions before entering the work that were influencing their work performance. The managerial style provoked the observed deterioration of mental health status. Lack of knowledge of worker's rights let the employer disregard aspects of the law in a society generally thought to have a well-regulated labour marked. It is of importance to psychiatric treatment, even in a private practice, to have a view on the total situation of the patients, somatic, family and work conditions.

\section{Conflicts of Interest}

The author declares no conflicts of interest regarding the publication of this paper.

\section{References}

[1] Stevenson, M. and Duxbury, L. (2018) Overloaded and Stressed: A Case Study of Women Working in the Health Care Sector. Journal of Occupational Health Psychology, 1-13. https://doi.org/10.1037/ocp0000111

[2] Albertsen, K., Rugulies, R., Garde, A.H. and Burr, A.H. (2010) The Effect of the Work Environment and Performance-Based Self-Esteem on Cognitive Stress Symptoms among Danish Knowledge Workers. Scandinavian Journal of Public Health, 38, 81-89. https://doi.org/10.1177/1403494809352104

[3] Lundqvist, D., Fogelberg Eriksson, A. and Ekberg, K. (2018) Managers' Social Support: Facilitators and Hindrances for Seeking Support at Work. Work, 59, 351-365. https://doi.org/10.3233/WOR-182690

[4] Sterud, T., Tynes, T., Sivesind Mehlum, I., Veiersted, K.B., Bergbom, B., Airila, A., Johansson, B., Brendler-Lindqvist, M., Hviid, K. and Flyvholm, M.-A. (2018) A Systematic Review of Working Conditions and Occupational Health among Immigrants in Europe and Canada. BMC Public Health, 18, 770-785. https://doi.org/10.1186/s12889-018-5703-3

[5] Berg, J. and Grimeland, J. (2013) Leadership by Fragmented Destruction after a Merger: An Example from a Facility of Acute Psychiatry. Mental Illness, 5, 38-40. https://doi.org/10.4081/mi.2013.e11

[6] Orgel, D.L., Milliron, M. and Frederick, L. (1992) Musculoskeletal Discomfort in Grocery Express Checkstand Workers. An Ergonomic Intervention Study. J Occup Med, 34, 815-818. 